\title{
Preface: Insights from environmental tracers in groundwater systems
}

\author{
Ward E. Sanford • Werner Aeschbach-Hertig • \\ Andrew L. Herczeg
}

\section{Historical perspective}

Hydrogeology developed into an independent field of scientific study over the course of the twentieth century. In the first part of the century, focus was mostly on resource development from aquifers, which depended primarily on an understanding of aquifer hydraulics through changes in water levels, with less focus on the actual movement of groundwater. By the middle of the century, water-quality interests had led to the development of groundwater geochemistry as a scientific field to understand the character and genesis of the natural constituents in groundwater (Foster 1950; Chebotarev 1955; Hem 1970). The discussion of chemical constituents in groundwater in textbooks continued to take a back seat to that of flow hydraulics, and the focus was either on water-quality concerns or upcoming issues pertaining to the transport of chemical pollutants (Todd 1959; Davis and DeWiest 1966; Freeze and Cherry 1979). The fields of physical and chemical hydrogeology were still separate from a practical standpoint illustrated by the fact that the historical contributions, well through the middle of the century, were most easily divided this way (Freeze and Back 1983; Back and Freeze 1983).

With the development of mass spectrometers in the middle of the twentieth century and their improvements in accuracy and efficiency during the rest of the century, isotopic measurements of chemical tracers in groundwater

Received: 5 November 2010 / Accepted: 16 November 2010

Published online: 9 December 2010

(C) Springer-Verlag (outside the USA) 2010

W. E. Sanford (

United States Geological Survey, MS 431,

12201 Sunrise Valley Drive, Reston, VA 20192, USA

e-mail: wsanford@usgs.gov

W. Aeschbach-Hertig

Institute of Environmental Physics,

University of Heidelberg,

Im Neuenheimer Feld 229, 69120 Heidelberg, Germany

A. L. Herczeg

CSIRO, Land and Water,

Private Mail Bag 2, Glen Osmond, SA 5064, Australia became commonplace and the focus turned more toward movement of groundwater. The atmospheric nuclear testing in the late 1950s and early 1960s also created a convenient input signal to trace movement of tritium through the shallow hydrosphere during the rest of the century (Begemann and Libby 1957). At about that time (1961), the International Atomic Energy Agency (IAEA) began measurements for a Global Network of Isotopes in Precipitation (Aggarwal et al. 2007). Nuclear tests also released carbon-14 and chlorine-36 to the atmosphere, and introduction of other environmental tracers of anthropogenic origin such as chlorofluorocarbons (CFCs) and sulfur hexafluoride $\left(\mathrm{SF}_{6}\right)$, soon followed. At the same time, physical hydrogeologists became aware that natural environmental tracers were good tools for understanding how groundwater moved through the subsurface over a broad range of time scales. Dating water by use of chemical and isotopic tracers yielded not only valuable conceptual information about residence times of water in aquifers, but also could be used to calibrate numerical groundwater-flow models. Thus, by the end of the century, environmental tracers had become an important field of study within groundwater geochemistry (Clark and Fritz 1997; Cook and Herczeg 2000). Today, in the twenty-first century, environmental tracers are critical tools that are used in many groundwater studies. Environmental tracers give information on current and past flow conditions that is independent of what can be determined by hydraulic analyses alone.

\section{Current state-of-the-art}

The intent of this theme issue is to present a group of papers that describe aspects of the current state-of-the-art in using environmental tracers to gain insights into groundwater-flow systems. Rather than focusing on the methodologies of the different techniques, the idea behind the theme issue is to demonstrate how environmental tracers are best applied in hydrogeology and what knowledge on the studied groundwater systems can be gained from their use. Most environmental tracer systematics by now have been well established through a number of proof-of-principle studies conducted in geochemically and hydraulically simple aquifers. The challenge now lies in improving the way they are put to use by the community 
of hydrogeologists in the more complex systems that are usually being considered. Environmental tracers should by now be an integral part of the hydrogeologists' toolbox, to be combined with hydraulic and hydrogeochemical data as well as groundwater modeling. This modern approach is reflected by the papers of this issue.

This theme issue consists of three essays, two review papers, and 16 regular papers. There is a substantial geographic diversity to the studies presented, with sites or authors from five continents and 15 countries. Topics include age dating, use of multiple tracers, source delineation, heat as a tracer, and constraining groundwater-flow models. In the following, the essays and reviews are discussed before providing a brief summary of the regular papers in this issue.

The essays are on three separate topics. Aggarwal et al. give a summary of the measurement and use of isotopes at the IAEA and the pioneering role the IAEA has played in promoting their use across the world. Shapiro discusses the role of environmental tracers in fractured and carbonate rocks, with emphasis on trying to understand the extreme heterogeneity present in those complex environments. Sanford gives a summary of how ages can be used to calibrate groundwater models, with an emphasis on practical considerations rather than what is theoretically possible.

The two review papers each summarize developments in a more specific application of tracers. Herczeg and Leaney summarize the use of tracers in arid zones. There is some emphasis on the work that has been done in Australia and several suggestions for future research directions. Saar reviews the use of heat as a tracer. More specifically he emphasizes the use of geothermal heat flux and gradients measured in boreholes to determine characteristics of groundwater flow. The paper by Zuber et al., though not a formal review paper, does review the difficulties in defining the meaning of a groundwater "age" and the interpretation of tracers to represent such an age; this paper also discusses the use of lumped-parameter models at length.

It is impossible to uniquely classify the papers in this issue into simple categories either according to the tracers used or the systems to which they are applied. As is typical for modern tracer studies, multiple tracers have been applied whenever possible; this approach proves to be greatly advantageous in better constraining groundwater flow conditions. As a result and in accordance with the goals of this issue, the following summary of papers is generally oriented along with the major hydrogeological questions that have been addressed in the studies.

A number of authors discuss the role of general waterquality parameters and the major elemental composition of the dissolved solutes in improving the understanding of general features of the particular flow system. Yechieli and Sivan describe the effect of confining layers on salinity patterns in coastal aquifers. They present the differences that both the hydrogeology and salinity create in the coastal aquifers of the Mediterranean Sea and Dead Sea in the Middle East. Mendizabal et al. describe how a detailed mapping of solute chemistry in The Netherlands has led to a better understanding of the flow system and its spatial distribution. Stotler et al. describe the distribution of the hydrogeochemistry of a complex glacial aquifer in Canada, with the use of the chemistry to help determine the potential locations of hydraulic "windows". Carreira et al. discuss the use of chemistry and isotopes to define the dynamics of groundwater in a mountainous area and to delineate thermal waters in the source areas in Portugal.

Still other authors focus on the role of isotopes in delineating the particular areas that are the sources of recharge and the timing of that recharge. Parisi et al. use stable isotopes of groundwater in a volcano in Italy to determine the location of the recharge areas. Wood also uses stable isotopes, but in the arid climate of Abu Dhabi, United Arab Emirates, where the data help to determine both the source location of the water and its recharge during the last wet period 5,000-9,000 years ago. Similarly, Chen et al. report on the use of stable isotopes and carbon-14 to identify and date the recharge sources of the multi-aquifer flow system in the Songnen Plain of northeastern China.

In addition to locating recharge sources in space and time, environmental tracers have frequently been used to estimate recharge rates and to study recharge processes in particular settings. Huang and Pang use the chloride massbalance method to estimate recharge rates after land-use change in central China. Solomon et al. use dissolved gases to study recharge processes that are associated with artificial recharge in southern California and their effect on dissolved gases.

Other authors describe tracers in groundwater systems that are used primarily to determine ages and mean residence times. Murphy et al. use tritium and helium in a shallow, contaminated system in Ontario, Canada, to calibrate a groundwater flow and transport model. Zouari et al. use carbon-14 in a regional aquifer in Tunisia to estimate residence times and regional flow-system dynamics. Sültenfuß et al. report on a study of a coastal groundwater system in Germany. In addition to using tritium, helium, and carbon-14, this is one of the few reported studies to successfully use argon-39 as a dating tracer.

Finally, a number of studies extend the use of environmental tracers from aquifers into confining units and water at the pore scale. Ali et al. measure helium in cores of the deep drillhole into the San Andreas Fault in California, USA, using these data to determine the porosity of the rocks rather than for dating. Tokunaga et al. use carbon-14, chlorine-36 and chlorine-37 in groundwater and pore waters to examine the slow movement of water across a coastal confining layer in Japan. Hendry and Wassenaar have also studied a confining unit, but, in their case, they summarize results from a number of tracers that have been used in a shallow glacial till in west-central Canada. 


\section{Future directions}

As we continue into the twenty-first century, it can be foreseen that environmental tracers will continue to be an important tool for better understanding of groundwater systems (Glynn and Plummer 2005). Guidebooks on these methods have been and are currently being written by international agencies (IAEA 2006, 2011) such that their use can become more commonplace around the world. A selection of papers from a recent workshop focusing particularly on groundwater dating by using environmental tracers has recently appeared (Osenbrück et al. 2010). These methods are now being used more frequently and widely than ever, and their development continues to be dynamic. For example, new environmental tracers have been suggested (Busenberg and Plummer 2008) and a new analytical technique has had a successful start (Sturchio et al. 2004) in recent years. Inverse methods for calibrating groundwater models are being used more routinely (Hill and Tiedeman 2007) and there is an increasing awareness from the mathematics of model calibration that head-independent data are vital for constraining models. Environmental tracers are an ideal source of such data. Older groundwater reservoirs are also being recognized as retaining records of past climate changes, because tracers that have entered via the atmosphere often do not mix to the extent that the temporal signal is lost. The articles presented in this issue not only describe the current state-of-the art, but also should inspire today's groundwater scientists to continue to explore new methods and apply them to new sites in the future.

\section{References}

Aggarwal PK, Froelich K, Gonfiantini R, Gat JR (2007) Isotope hydrology: a historical perspective from the IAEA. In: Aggarwal PK, Gar JR, Froelich KFO (eds) Isotopes in the water cycle. Springer, Dordrecht, The Netherlands
Back W, Freeze RA (1983) Chemical hydrogeology. Benchmark Papers in Geology 73, Hutchinson Ross, Stroudsburg, PA

Begemann F, Libby WF (1957) Continental water balance, ground water inventory and storage times, surface ocean mixing rates and world-wide circulation patterns from cosmic-ray and bomb tritium. Geochim Cosmochim Acta 12:277-296

Busenberg E, Plummer LN (2008) Dating groundwater with trifluoromethyl sulfurpentafluoride $\left(\mathrm{SF}_{5} \mathrm{CF}_{3}\right)$, sulfur hexafluoride $\left(\mathrm{SF}_{6}\right), \mathrm{CF}_{3} \mathrm{Cl}$ (CFC-13), and $\mathrm{CF}_{2} \mathrm{Cl}_{2}$ (CFC-12). Water Resour Res 44:W02431. doi:10.1029/2007WR006150

Chebaterov II (1955) Metamorphism of natural waters in the crust of weathering-1. Geochim Cosmochim Acta 8:22-32

Clark ID, Fritz P (1997) Environmental isotopes in hydrogeology. Lewis, New York

Cook P, Herczeg AL (2000) Environmental tracers in subsurface hydrology. Kluwer, Boston

Davis SN, DeWiest RJM (1966) Hydrogeology. Wiley, New York Foster MD (1950) The origin of high sodium bicarbonate waters in the Atlantic and Gulf coastal plains. Geochim Cosmochim Acta $1: 33-48$

Freeze RA, Back W (1983) Physical hydrogeology. Benchmark papers in geology 72. Hutchinson Ross, Stroudsburg, PA

Freeze RA, Cherry J (1979) Groundwater. Prentice-Hall, Hoboken, NJ

Glynn PD, Plummer LN (2005) Geochemistry and the understanding of ground-water systems. Hydrogeol J 13:263-287

Hem JD (1970) Study and interpretation of the chemical characteristics of natural water. US Geol Surv Water Suppl Pap 1473

Hill MC, Tiedeman CR (2007) Effective groundwater model calibration. Wiley, Hoboken, NJ

IAEA (International Atomic Energy Agency) (2006) Use of chlorofluorocarbons in hydrology: a guidebook. IAEA, Vienna

IAEA (International Atomic Energy Agency) (2011) Dating old groundwater: a guidebook. IAEA, Vienna, in press

Osenbrück K, Weise SM, Newman BD (2010) Selected papers from the international workshop G-DAT 2008: groundwater dating using environmental tracers. Isot Environ Health Stud 46:257-258

Sturchio NC, Du X, Purtschert R, Lehmann BE, Sultan M, Patterson LJ, Lu Z-T, Müller P, Bigler T, Bailey K, O'Connor TP, Young L, Lorenzo R, Becker R, El Alfy Z, EI Kalioubly B, Dawood Y, Abdallah AMA (2004) One million year old groundwater in the Sahara revealed by krypton81 and chlorine-36. Geophys Res Lett 31:L05503. doi:10.1029/ 2003GL019234

Todd DK (1959) Groundwater hydrology. Wiley, New York 